\title{
Folk Culture in the Digital Age: The Emergent Dynamics of Human Interaction. Edited by
}

\section{Trevor J. Blank. Boulder, CO: Utah State University Press, 2012. 262 pp. Illus. \$29.95}

\section{(pbk/e-book), ISBN 978-0-87421-889-3 (pbk), ISBN 978-0-87421-890-9 (e-book)}

A remarkable volume; the addition of $Q R$ codes (a matrix barcode that is read by a smartphone or other mobile device) throughout is not only representative of the consideration given to its compilation, but also provides useful, dynamic references to the materials discussed. Folk Culture in the Digital Age begins with a well-referenced account of the computer's birth and the incipience of the counter-culture that grew in parallel, through movements and publications such as the 'homebrew computer club' newsletter (c.1974). This culture is further delineated as an expressive vernacular behaviour dialectically opposed to the dominant institutional culture that presided during the 1960s. Robert Howard's assessment of modern-day communications, such as YouTube and Facebook, applies postcolonial criticism to the contemporary situation. Perhaps more could have been made of the irony, in the suggestion that the purposefully non-institutional constructions of the original counter-culture paved the way for a vernacular web of expressions that are nonetheless transmitted through an institutional framework of software. However, the way in which individuals are given the opportunity to create a vernacular that enacts its otherness from the institutional is admirably explored. Indeed, how the vernacular is limited, restricted by, or sometimes opposed to the arena in which it is produced is thoughtfully posed as necessarily hybrid.

Chapter Two creates a more solid theoretical framework and concerns itself with the post-national citizen, the Netizen, who is taking part in a global discourse wherein the traditional link of culture, and thus identity, with geography is no longer relevant. Therefore, Tok Thompson's wink by using the term 'Folklore 2.0 ' in 'Netizens, Revolutionaries, and the Inalienable Right to the Internet' (58) seems entirely appropriate as a way of ruminating over the new 'glocal' folk (56), as does Anthony Buccitelli's next chapter title: 'Performance 2.0 '. There is another reiteration in this chapter, which perhaps goes a long way towards summing up the volume: Buccitelli points out that Trevor Blank comments in the introduction on 'the extent to which the criterion of "face to face" contact has permeated the study of folklore performance' and how this has greatly contributed to the 'reluctance of folklorists to study digital folklore as performance' (61). While Elliott Oring (98-99) echoes this sentiment in the fifth submission, it perhaps also explains his noticeable reluctance to fully commit to the fact-a marked shame within the chapters. The quite 
reductive, even limited, potential conceptualizations that are laid out by Oring in his introduction, of how and where folklore exists on the Web, do not fully appreciate the new dynamism which is occurring within the discipline and its relation to contemporary society. Granted, this was not the remit of the piece (to tackle the evolving arena of operations), and it is otherwise meticulously observant in its reported detail and interpretation. Indeed, the wisely noted push toward visual imagery in digital humour is indicative of this.

Contrary to the aforementioned gripe, and moving back to the third chapter, there is a productive and informed consideration of the indistinct parameters of the digital performance and how the varying types of expressions or events either benefit or suffer as a result. This is Downloaded by [University of Chester], [Simon Poole] at 02:51 10 March 2016 Book Reviews 363

reminiscent at times of Hermann Bausinger's (1961) 'horizons' when he discussed folklore through the lens of a technological world.

Interestingly, the reader may also notice in this chapter the precise observation that digital folklore has more frequently considered text and transmission rather than performance and digital technology. While Oring's writing perhaps subscribes to this phenomenon (a more 'traditional' perspective), Simon Bronner in the sixth chapter begins his intricately balanced piece by positioning his views alongside Smith's (1991) nearly prophetic realization that 'many colleagues wedded to definitions of folklore around face-to-face oral transmission might be skeptical of his folkloric label' (119). He continues with great flourish to unravel some of the more perturbing and evasive issues surrounding the expressive, interactive features and cultural functions of folklore online.

Simon Bronner, Bill Ellis, and Montana Miller, in the final chapters 'The Jewish Joke Online: Framing and Symbolizing Humor in Analog and Digital Culture' (119-49), 'Love and War and Anime Art: An Ethnographic Look at a Virtual Community of Collectors' (166-211), and 'Face-to-face with the Digital Folk: The Ethics of Fieldwork on Facebook' (212-32), manage to discuss with mastery the digital social setting. They all reorganize the cultural frames pertinent to their subject matters, rather than trying to squash the newly created expressive forms into frames that were adequate for traditions from a different age. In short, this is what this book as a whole does exceptionally well. It feels as though, finally, we have a collection of strong voices that have recognized the organic nature of tradition and the need to constantly re-clarify, re-justify, 
and rethink traditions within varying, new, and changeable social parameters.

Possibly the chapter that epitomizes this notion and the need for an open-minded, ever-changing appreciation of how the folk, folklore, and the discipline itself are developing is Lynne McNeill's fourth inclusion, 'Real Virtuality: Enhancing Locality by Enacting the Small World Theory' (85-97). This represents a detailed investigation into social reality as it stands, and considers how multi-localities and trans-localities enhance individual experiences within the framework of a 'small world theory'. Seemingly sharing a similar perspective as the authors in previous chapters, it is an articulate, and matter of fact, recognition that the virtual world should be recognized as part of the physical world, and that vernacular digital communication is essentially redefining the folk.

McNeill goes on to suggest, through a wonderful array of examples, how contemporary traditions are being created, crafted, and passed on through a, not necessarily always equal, co-existence (or even co-dependence) of the analogue and the digital. Furthermore, McNeill demonstrates that the will for a deep interconnectedness still pervades culture, as it always has, and with subtlety and poignancy gives a nod to the folklorist to uncover the ways in which it is now manifested. While these re-conceptualizations are well understood and remarkably well explained, the potential impolite and awkward situations of underdeveloped, unconfirmed, shared customs that we face in this new social reality do not escape McNeill, and the conclusion offers a tidy view of the situation through a macro, albeit multi-localized, lens.

\section{Simon Poole, University of Chester, UK}

\section{(C) 2015 Simon Poole}

